DOI: $10.15593 / 2224-9354 / 2021.3 .9$

УДК 316.4.05:303.44

\title{
Г.А. Волковицкая
}

\section{ПРОБЛЕМНЫЕ АСПЕКТЫ МЕТОДОЛОГИИ ИЗМЕРЕНИЯ КАЧЕСТВА ЖИЗНИ}

\begin{abstract}
Индекс человеческого развития обеспечил веху для отслеживания прогресса в развитии человека, что повлекло множество позитивных последствий в структуре представлений о человеческой эволюции и, в частности, изменение формулы развития, где на первое место вышел сам Человек, что можно считать благоприятной парадигмальной основой для улучшения благосостояния, как мира в целом, так и сообществ отдельных стран. В наши дни значимость индекса человеческого развития обретает новую ценность, что предполагает необходимость учесть новые измерения.

Гуманистический подход как структурная основа индекса человеческого развития показал, что современный мир масштабирует диапазон выбора для каждого, кто готов к самосовершенствованию, обучению, созидательному труду. По мнению автора, разработка индексов невозможна без учета творческого потенциала наций, а также индивидуалистических особенностей, которые уже имеют характеристики глобального масштаба.

В данной работе рассматриваются понятия устойчивости (экологичности) труда как ключевого элемента международного индекса счастья и благополучия. Проведен анализ вариации индекса доверия, который базируется на творческом развитии, с учетом инновационных возможностей, связанных с патентованием. Как доказательный вариант в цепочке экологичность труда - творческое развитие, приведена статистика патентования и регистрации стартапов. По мнению автора, новым индикатором, способным оценить эффективность управленческих мер, может стать доверие. Речь идет о возможности его использования как для расчетов, так и для решения существующих глобальных вызовов. Релевантность индекса доверия ранжируется способностью оперативного реагирования при оценке мер государственной политики. Также он подходит для оценки уязвимости экономических индикаторов и факторов в период кризисов.

Ключевые слова: индекс человеческого развития, патентование, доверие, устойчивость труда, экологичность труда.
\end{abstract}

Введение. Индекс человеческого развития (ИЧР) / Human Development Index (HDI) - показатель, который оценивает развитие человека в большинстве стран и регионов планеты [1]. Комбинированная формула рассчитывается ежегодно экспертами Программы развития Организации Объединенных Наций (ПРООН) в тесном сотрудничестве с независимыми экспертами-международниками. Разработанные индексы базируются на статистических данных, аналитических разработках национальных институтов, международных организаций [1]. Понятие человеческого развития подразумевает набор прерогатив, с акцентом на долгой и здоровой жизни [2], расширение человеческого потенциала, расширение охвата и возможности выбора, создание благоприятных возможностей для человека [3]. В течение многих лет ИЧР успешно воплощал

(С Волковицкая Г.А., 2021

Волковицкая Галина Андреевна - канд. социол. наук, доцент кафедры управления образованием и кадрового менеджмента Института экономики и управления ФГБОУ ВО «Российский государственный педагогический университет им. А.И. Герцена», e-mail: galialap@mail.ru. 
в жизнь трудоемкие результаты исследований, отображая картину человеческого развития в исследуемых странах. Авторитетность ООН, глубокое уважение и доверие к институтам этой международной организации не ставят под сомнение методологию расчетов и аналитических формулировок, что обусловило огромный рывок в исследованиях по ИЧР во всем мире [1]. Следует отметить, что многие страны показали значительный прорыв в развитии экономики [3], социальных показателях [4], общественного развития [5], именно благодаря этим исследованиям. Следовательно, их индексы также прогрессировали. В этой связи эволюция в измерениях и формулировках становится объективной необходимостью. Контроверсия в методологических подходах должна быть устранена и быть адаптирована под современные требования, с учетом достижений человечества. Новые индексы ИЧР, которые добавлены к действующим в 2010 г., а именно: ИЧРН - Индекс человеческого развития, скорректированный с учетом социально-экономического неравенства, ИГН Индекс гендерного неравенства [6], ИМБ - Индекс многомерной бедности, опираются на среднестрановый [1] показатель (ИЧР имел свои недостатки, что было откровенно признано его составителями), вновь нуждаются в совершенствовании.

Процесс глобализации изменил обличие планеты [1], способы жизнедеятельности [3], способы мышления и действий [7]. Можно выделить ключевые проблемы, которые были актуализированы произошедшими изменениями в течение последних десятилетий. В связи с глобальным масштабированием нависли серьезные угрозы для человечества, которые можно структурировать следующим образом:

- неравенство общества - социальное, финансовое, дискриминационное в общегосударственном масштабе [6];

- безопасность - несмотря на миролюбивые декларации политиков, безопасность человечества стала более ущемленной [8];

- климатические изменения - оказывают воздействие не только на жизнедеятельность, но и на саму жизнь человека [9];

- политические - идейный кризис мира, стремление к политической свободе [6].

Вопросы оценки человеческого капитала через призму существующих концептуальных разработок не проработаны до конца и требуют более конструктивного измерения. Кроме того, стоит вопрос о целевых ориентирах оценивания [10]. Если главной задачей измерений является решение существующих вызовов, то противоречивые данные ставят под сомнение достоверность некоторых показателей (особенно по вопросам статистики доходов). Очевидно, что среднестатистический показатель не способен идентифицировать индивидуальные и коллективные показатели [11] или региональные (территориальные, национальные) показатели имеют тенденцию к «приукрашиванию» результа- 
тов (к примеру, доходы в Санкт-Петербурге и доходы в Курске имеют существенные различия, а их средний показатель не отображает реальную картину). Обобщение не всегда оправданно и уместно, особенно, когда задействованы человеческие активы, интересы, надежды и перспективы. Компенсаторный аспект статистических показателей характеризуется противоречивостью. Индивидуальные показатели смываются или теряют свою ценность, продуцируя асимметричность распределения информации [11]. Но уже сегодня необходимость новой корректировки вызвана изменениями, происходящими в отдельных государствах. Актуальным станет рассмотрение цепочки «экологичность труда - творческие последствия устойчивости труда - доверие»как результат отношения к политической системе и ко всем другим показателям. Еще Ф. Фукуяма считал, что успех капитализма в различных сообществах определяется не столько финансовыми факторами, сколько доверием. Именно оно сможет гарантировать экономическое благополучие общества. В своей книге «Великий разрыв» Ф. Фукуяма анализирует рост недоверия между людьми, кризис доверия к общественным институтам и друг к другу, подчеркивая, что именно доверие отражает способность людей объединяться вне пределов семьи и без тотального контроля государства [12].

\section{Объекты исследования.}

1. Экологичность понятия труд. Современные условия человеческого труда подразумевают целый ряд вопросов, связанных с условиями и социальными запросами общества. Не затрагивая такие важные критерии, как безопасность труда, наличие постоянной работы и др., следует обратить внимание на факторы, которые содействуют установлению социальных ценностей труда. Индивидуальные критерии могут быть разными, но преимущественно можно вывести аспекты закономерных условий удовлетворенности, которые имеют общие характеристики. Также можно утверждать, что они могут быть едиными как для развитых стран, так и для развивающихся. В поисках данных критериев достаточно задать несколько вопросов:

- Доставляет ли труд удовольствие?

- Удовлетворены ли люди своим трудом?

- Есть ли возможность карьерного роста?

- Есть ли перспектива для роста заработной платы?

- Представляется ли возможность сбалансировать труд и личную жизнь?

- Отсутствует ли дискриминация (все виды дискриминации, включая гендерные, национальные и др.)?

Обозначенные вопросы, по большому счету, можно отнести к сфере психологических критериев, но именно психологическая удовлетворенность (или неудовлетворенность) способствует творческому развитию человека. Иными словами, качество работы влияет на экологическую устойчивость отношения индивида к труду. К примеру, сравним труд квалифицированного доктора- 
хирурга из Канады и квалифицированного доктора-хирурга из Замбии. Имея одинаковую задачу, оба хирурга выполняют ее в совершенно разных условиях. Другими словами, два пациента с одинаковым диагнозом по-разному перенесут операции, и это никоим образом не связано с профессиональностью доктоpa, а скорее всего с условиями или материально-технической базой медицинского заведения. В 2010 г. произошла корректировка формулы ИЧР, что стало следствием накопления производительных способностей людей.

2. Патентование как показатель творческой активности граждан. Нематериальные капиталы общества стали главным арсеналом некоторых развитых государств, что всячески содействует творческому развитию личности, особенно в последние десятилетия. Именно творческую потенцию граждан сегодня рассматривают как основной драйвер экономического роста. Инновационный потенциал каждой страны определяется некоторыми факторами, которые могут содействовать повышению индекса человеческого развития. Одним из таких факторов можно считать активизацию патентной деятельности. Изобретения и внедрения инновационных благ можно рассматривать как один из показателей уровня человеческого благосостояния, индикаторов проявления творческого мышления и творческого потенциала общества. Например, если задать в поисковом окне The United States Patent and Trademark Office (USPTO) http://patft.uspto.gov/netahtml/PTO/search-adv.htm запросы вида: ICN/код страны, то можно получить число патентов, зарегистрированных за изобретателями - гражданами данной страны, можно найти, что для развитых стран число патентов будет много выше такового для стран развивающихся. Так, число патентов, зарегистрированных гражданами США, - 1958 188, а гражданами Афганистана - 5. Следует оговориться, что в счет идут только международные патентные заявки и столь малым числом патентов возможно не ограничивается инновационная деятельность в Афганистане, но порядок величин очевиден.

Информационная революция, мобильность рынка и высококвалифицированных специалистов, особенно тех, кто имеет потенциал к творческому новаторству, ставит проблему на уровень глобального масштаба. Интеллектуальная деятельность общества в сфере инноваций должна быть не только прогнозирована, но и защищена на самом начальном уровне, а реализация образовательных программ по патентованию должна стать одним из способов, подтверждающих государственную заинтересованность в этом виде деятельности. В образовательных программах должна быть прописана стандартизированная модель подготовки кадров, как технических, так и экономических направлений, что в дальнейшем может интенсифицировать инновационный рынок России, предполагающая:

- создание особенных условий для патентования, благоприятных для интенсификации деятельности стартаперов;

- создание специализированных факультетов и институтов, где патентование станет главной специализацией; 
- введение новых специальностей, особенно технического профиля. В качестве эксперимента для апробации можно предложить введение факультативов по направлениям «Патентование в России и за рубежом» или «Инновации и изобретательская деятельность»;

- введение в образовательные программы по практике создание виртуального патента для студентов технических специальностей, с учетом всех перспектив, в том числе финансовых;

- осуществление совместно с научно-исследовательскими институтами инновационных проектов и многое другое.

Акцентирование внимания на активизации деятельности студенческой молодежи покажет заинтересованность государства в подготовке новых кадров и будет способствовать росту уровня доверия к возможностям реализации федеральных государственных программ. Это будет формировать доверие со стороны общества, способного оценить вектор государственного инвестирования. Инвестируя в образовательные проекты, стимулируя активизацию рационализаторских способностей, государство сможет не только защитить свой интеллектуальный ресурс, но и способствовать развитию новой программы по интеллектуальному конструированию модели конкурентоспособных патентов.

Эмпирические данные. Особого внимания, на наш взгляд, заслуживает вопрос об «утечке инноваций». С целью анализа динамики миграции интеллектуальной собственности воспользуемся данными The United States Patent and Trademark Office (USPTO), в поисковом окне http://patft.uspto.gov/netahtml/PTO/ search-adv.htm с помощью поискового запроса ISD/2019 AND ICN/RU определим численность международных патентов российских изобретателей за исследуемый период 1992-2019 гг. (2020 г. нами не учитывался из-за ситуации с пандемией новой коронавирусной инфекции, так как данные могут не отражать сущность исследуемого явления, а быть результатом отсутствия альтернатив инновационного поведения). Дифференцируя показатели временного лага, получим распределение активности изобретателей по временному критерию. А с помощью поискового запроса ISD/2019 AND ICN/RU ANDNOT $\mathrm{PRIR/RU}$ определим долю патентов российских изобретателей, страной приоритета в которых названа не Россия. Считаем этот показатель достаточно хорошо характеризующим состояние миграции интеллектуальной собственности и инновационных идей.

Анализируя данные рис. 1, 2 и таблицы следует отметить, что большая часть российских изобретателей, выводящих свои работы на международный уровень, не стремится указывать РФ страной приоритета, т.е. не видят будущего у своей работы в РФ. Был период, когда доля таких изобретателей устойчиво сокращалась, тенденция нарушалась только в кризисные годы, а в последнее время становится даже более выраженной (см.: кривую $A$ на рис. 2 и поведение линии тренда на рис. 1). 


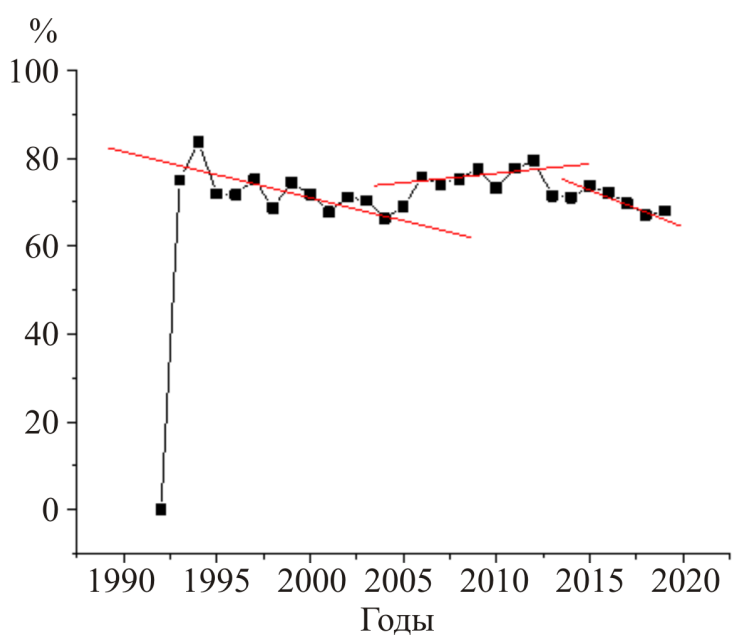

Рис. 1. Динамика международных патентов российских изобретателей, страной приоритета в которых является не РФ

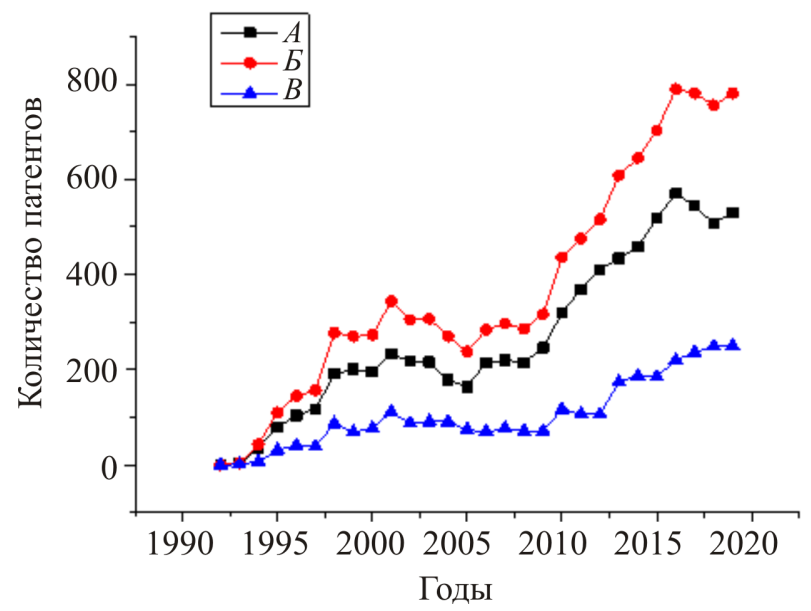

Рис. 2. Динамика международной активности российских изобретателей (см. таблицу)

В общий инновационный фонд можно отнести и стартапы, которые весьма популярны среди молодежи разных стран. Среди лидеров государства Америки и Азии; популярности в этой сфере набирают и другие регионы. В России множество молодых предпринимателей успешно воплощают свои идеи, большинство из которых уникальны и, по меньшей мере, бросают вызов традиционным методам ведения бизнеса, занятости. Тем не менее инновационность идей не гарантирует успешность. Далеко не всем удалось продвинуть свой бизнес даже при условии отличной идеи. В первую очередь проблема лежит в плоскости финансирования стартапов и несовершенства юридической государственной защищенности. В поисках «финансовых анге- 
лов» молодежь стремится искать денежных доноров в странах более благополучных. Доказательством этого может быть пример Кремниевой долины в США, что «приютила» молодых предпринимателей со всего мира, и стала одним из мест скопления высокотехнологических предприятий только потому, что политика инвестирования в США открывает перспективы инновационным идеям.

Динамика «мигрирующих» патентов российских изобретателей в период 1992-2019 гг. (см. рис. 2)

\begin{tabular}{|c|c|c|c|}
\hline Год & $\begin{array}{c}\text { Число международных } \\
\text { патентов российских } \\
\text { изобретателей, страной } \\
\text { приоритета которых } \\
\text { заявлена не РФ. Кривая } A\end{array}$ & $\begin{array}{c}\text { Число международных } \\
\text { патентов российских } \\
\text { изобретателей. } \\
\text { Кривая } \overline{ }\end{array}$ & $\begin{array}{c}\text { Число международных } \\
\text { патентов российских } \\
\text { изобретателей, страной } \\
\text { приоритета которых } \\
\text { заявлена РФ. Кривая } B\end{array}$ \\
\hline 1992 & 0 & 0 & 0 \\
\hline 1993 & 3 & 4 & 1 \\
\hline 1994 & 36 & 43 & 7 \\
\hline 1995 & 79 & 110 & 31 \\
\hline 1996 & 104 & 145 & 41 \\
\hline 1997 & 118 & 157 & 39 \\
\hline 1998 & 191 & 278 & 87 \\
\hline 1999 & 201 & 270 & 69 \\
\hline 2000 & 196 & 273 & 77 \\
\hline 2001 & 233 & 344 & 111 \\
\hline 2002 & 217 & 305 & 88 \\
\hline 2003 & 216 & 307 & 91 \\
\hline 2004 & 179 & 270 & 91 \\
\hline 2005 & 164 & 238 & 74 \\
\hline 2006 & 215 & 284 & 69 \\
\hline 2007 & 220 & 297 & 77 \\
\hline 2008 & 215 & 286 & 71 \\
\hline 2009 & 246 & 317 & 71 \\
\hline 2010 & 319 & 436 & 117 \\
\hline 2011 & 369 & 475 & 106 \\
\hline 2012 & 410 & 516 & 106 \\
\hline 2013 & 434 & 608 & 174 \\
\hline 2014 & 458 & 645 & 187 \\
\hline 2015 & 518 & 703 & 185 \\
\hline 2016 & 570 & 790 & 220 \\
\hline 2017 & 544 & 781 & 237 \\
\hline 2018 & 507 & 756 & 249 \\
\hline 2019 & 531 & 781 & 250 \\
\hline
\end{tabular}


Миграция талантливой молодежи вместе с инновационными идеями - явление крайне негативное для каждого государства, демонстрирующее ему (государству) дефицит доверия граждан к государственным институтам. В этой связи мы предлагаем этот простой показатель - число международных патентов граждан страны, которые не указали страной приоритета свою Родину, - рассматривать как косвенную характеристику доверия граждан к своей стране.

3. Устойчивость труда как элемент индекса счастья. Последствия глобализации на рынке труда очень разнообразны. Это не только аутсорсинг, но и оффшоринг (делегирование сотрудников), частичная занятость, удаленная работа и многое другое. Все большее число государств втягивается в эту рыночную игру. И, конечно же, это уже не только общеизвестная Индия. Страны Восточной Европы, Россия, Китай, Латинской Америки и многие другие уже вовлечены в процесс глобального международного миграционного процесса. Следствия таких масштабных явлений имеют статус глобальных. То, что происходит на рынке труда, можно назвать дефицитом квалификаций. Квоты востребованных квалификаций растут, а трудовой потенциал человечества не успевает до требуемого уровня. Высококвалифицированный работник занимает четкие позиции на глобальном (международном) рынке и претендует на самые лучшие условия.

Интенсификация технологий также вызывает проблему несоответствия квалификаций [13], гендерного неравенства [14]. Можно утверждать, что существует некоторое пространство, незаполненное, но очень критичное. Частично этот дисбаланс связан с тем, что за усиленными темпами инноваций человек просто не успевает. Некоторые европейские страны не могут заполнить требуемые вакансии только потому, что нет необходимых квалификационных навыков. Например, в Италии, Греции, Испании, несмотря на высокий уровень безработицы среди молодежи, около 50 \% свободных вакансий не закрываются по причине отсутствия специалистов необходимой квалификации. Следовательно, повышается рейтинг вакансии и ее стоимость. Уместным будет также вопрос об индивидуальных навыках морально-поведенческого плана. Добросовестность, мотивация, предусмотрительность, time-management, multy-tasking, soft skills и многие другие личностные характеристики играют немаловажную роль в современном понятии квалификации работника. Добросовестные работодатели, ценящие труд своих работников, делают условия труда предельно комфортными. Привлекательность некоторых офисов может удивить даже самых бывалых: это и кухни, бары, зоны отдыха, спортзалы, комнаты релакса (отдыха), услуги психолога и многое другое. Практика home-offices (офис-дом, где сотрудник может и жить, во многих случаях, бесплатно) создана для максимального комфорта работника.

Результаты исследования и обсуждение. Проведенный теоретический и эмпирический анализ показал, что произошли глубинные сдвиги в сознании 
и идеологии [13]. Преобразования просто поразительны во всех сферах. Если говорить о странах постсоветского пространства [8], то можно утверждать, что прогнозы Френсиса Фукуямы стали реальностью, как на политической, так и на социальной аренах. Совершено новые формы сообществ с их особенной ментальностью, характерной только для данных территорий, стали немаловажными игроками на арене мировой политики [1]. Конечно же, это кардинально разные социальные сообщества, но стремление к улучшению уровня жизни объединило их под единым политическим символом. Сегодня внешнеполитические курсы большинства европейских стран работают под эгидой гуманистических идеалов, направленных на совершенствование благосостояния и жизнедеятельности человека [17]. Недостатки ИЧР, в первую очередь, исходят из среднестатистического числа национальных отчетов, что не может отображать реальную картину индексов. Авторитетность структур ПРООН [1], конечно же, вызывает высокую степень доверия, но исследования базируются на национальных отчетах, которым в большей степени свойственны «приукрашивания» данных. Отсутствие объективной оценки - это вопрос другого исследования, но причины, по которым реальная картина не показывает существующих проблем [14], вводит в заблуждение мировое сообщество, - и все только для рейтинга, а не для улучшения уровня жизни [18]. Главным образом это относится к странам постсоветского пространства.

Индексы человеческого счастья [19] и благополучия [20] имеют тенденцию устаревать, а релевантность аналитики нуждается в новых критериях оценивания. Сравнительный анализ дифференциации индекса доверия в европейских и постсоветских государствах актуален в целях разработки и последующей реализации коррекционных мероприятий в интересах нынешних и будущих поколений. Недоверие молодого поколения к государственной политике иллюстрируют тенденции трудовой и интеллектуальной миграции населения, свидетельствующие об утрате личностного и коллективного человеческого ресурса.

Bbыводы. Индекс человеческого развития выступает одной из самых авторитетных характеристик общественного развития в мире. Международные индексы счастья и благополучия имеют свойства субъективных единиц, склонных к динамке и пластичности. Последние двадцать лет жизнедеятельности человека доказали эти утверждения в полной мере. Семантика понятий индексов эволюционировала и видоизменялась. По всей вероятности, современные трактовки, которым приписывают моральное старение, требуют корректировки. В цепочке индексов благосостояния и счастья должен быть указан также индекс доверия. Ранжирование индексов возможно по критерию регистрации патентов и стартапов, отражающему творческую самореализацию населения, готового к созидательному труду. В настоящее время, безусловно, особенные навыки и квалификация, самообразование, творческий подход, высокий уровень самоорганизации - именно те векторы человеческого развития, которые 
можно назвать творческими двигателями в системе устойчивости трудовой деятельности.

По мнению автора, новым индикатором, способным оценить эффективность управленческих мер, может стать доверие. Речь идет о возможности использования нового индикатора, как для расчетов, так и для решения существующих глобальных проблем и реагирования на глобальные вызовы, по крайней мере это необходимо в странах СНГ. Практику альтернативных индексов, которые были составлены на национальных показателях, уже использовали правительства Австралии, Ирландии и Великобритании (примерно в начале 2000-х). К примеру, Великобритания предлагает использовать расчеты не ВВП, а ВБП - валовое благополучие. Но такие формулы не могут отличаться достоверностью, поскольку субъективными выступают представления разных слоев общества о понятии благополучия. И как никогда актуальным для британцев может стать новый индекс, основанный на принципе доверия, особенно в свете нынешних событий, связанных с брэкзитом. Релевантность индекса доверия ранжируется способностью скорого реагирования в оценке мер государственной политики. Также он подходит для оценки уязвимости экономических и социальных факторов в период кризисов (экономических, природных катаклизмов, социальных кризисов, политических обострений и др.). Кроме того, доверие имеет все необходимые параметры, чтобы стать новым сегментом в формуле ИЧР. Можно также говорить о сущности семантического ядра данного понятия. Вырабатывать политические рекомендации, базируясь на доверии, актуально в условиях современной мировой политики.

Экологичность труда, комфортность труда в той формуле, в которой она была представлена еще двадцать лет назад, уже не актуальна. Высокие критерии квалификационных требований к работнику стимулируют человека к постоянному усовершенствованию. Творческий подход в трудовой деятельности должен преобладать, если индивид стремится идти в ногу со временем. Изобретательность как прерогатива интеллектуалов должна прежде всего служить национальным идеям, а не только быть товаром. Интеллектуальная собственность должна быть оценена не только в денежном эквиваленте, но и законодательно защищена государством.

\section{Список литературы}

1. Статистические данные и показатели: социальные индикаторы // Официальный сайт ООН. - URL: https://www.un.org/ru/databases/ (дата обращения: 16.04.2021).

2. McGillivray M. Human well-being: concept and measurement. - New York, 2006. -269 p.

3. McGillivray M. Human well-being: issues, concepts and measures // Studies in development economics and policy. - 2007. - № 15. - P. 1-22. 
4. Blanchflower D.G., Oswald A.J. Happiness and the Human development index: the paradox of Australia // Australian Economic Review. - 2005. - № 2. - P. 176-184.

5. Diener E. Subjective well-being: the science of happiness and a proposal for a national index // American Psychologist. - 2000. - № 55 (1). - P. 34-43.

6. Wickrama K.A.S., Charles L. Political democracy, economic development, disarticulation and social well-being in developing countries // The Sociological Quarterly. - 2016. - URL: https://www.tandfonline.com/doi/abs/10.1111/j.15338525.1996.tb00744.x (дата обращения: 18.03.2021).

7. Vemuri A.W., Costanza R. The role of human, social, built, and natural capital in explaining life satisfaction at the country level: toward a national wellbeing index (NWI) // Ecological economics. - 2006. - № 58 (1). - P. 119-133.

8. Fukuyama F. Trust: The social virtues and the creation of prosperity. - New York: Free press, 1995. -480 p.

9. Bravo G. The Human sustainable development index: new calculations and a first critical analysis // Ecological indicator. - 2014. - № 34 (A). - P. 145-150.

10. Fukuyama F. The End of History and the Last Man. - New York: Free press, 2006. $-446 \mathrm{p}$.

11. Böhringerab C., Patrick E.P. Jochem. Measuring the immeasurable - a survey of sustainability indices // Ecological economics. - 2007. - № 63 (1). - P. 1-8.

12. Fukuyama F. The Great Disruption: Human nature and the reconstitution of social order. - New York: Free press, 1999. - 354 p.

13. O'Neil P. Essentials of comparative politics. - New York; London, 2010. $781 \mathrm{p}$.

14. Charmes J, Wieringa S. Measuring Women's Empowerment: an assessment of the gender-related development index and the gender empowerment measure // Journal of Human Development. - 2003. - № 4 (Iss. 3). - P. 419-435.

15. Leigh A., Wolfers J. Happiness and the human development index: Australia is not a paradox // Australian Economic Review. - 2006. - № 39 (2). - P. 176-184.

16. Relating ecosystem services to domains of human well-being: foundation for a US index / L.M. Smith, J.L. Case, H.M. Smith, L.C. Harwell, J.K. Summers // Ecological Indicators. - 2013. - № 28. - P. 79-90.

17. Отчет по итогам деятельности Роспатента [Электронный ресурс]. URL: https://rospatent.gov.ru/content/uploadfiles/otchet_rp_2018.pdf (дата обращения: 17.04.2021).

18. McGillivray M., Clarke M. Understanding human well-being. - New York: United Nations University Press, 2006. - 386 p.

19. Wills E. Spirituality and subjective well-being: evidences for a new domain in the personal well-being index // Journal of Happiness Studies. - 2009. № 10 (1). - P. 49-69.

20. Delhey J., Kroll C. A «happiness test» for the new measures of national well-being: How much better than GDP are they? // Human happiness and the pursuit of maximization. - Springer, Dordrecht, 2013. - P. 191-210. 


\section{References}

1. Statisticheskie dannye i pokazateli: sotsial'nye indicatory [Statistics and data: Social indicators]. Available at: https://www.un.org/ru/databases/ (accessed 16.04.2021).

2. McGillivray M. Human well-being: Concept and measurement. New York, 2006, 269 p.

3. McGillivray M. Human well-being: Issues, concepts and measures. Studies in development economics and policy, London, 2007, no. 15, pp. 1-22.

4. Blanchflower D.G., Oswald A.J. Happiness and the human development index: The paradox of Australia. Australian Economic Review, 2005, no. 2, pp. 176-184.

5. Diener E. Subjective well-being: The science of happiness and a proposal for a national index. American Psychologist, 2000, no. 55 (1), pp. 34-43.

6. Wickrama K.A.S., Charles L. Political democracy, economic development, disarticulation and social well-being in developing countries. The Sociological Quarterly, 2016, available at: https://www.tandfonline.com/doi/abs/10.1111/ j.1533-8525.1996.tb00744.x (accessed 18.03.2021).

7. Vemuri A.W., Costanza R. The role of human, social, built, and natural capital in explaining life satisfaction at the country level: Toward a national wellbeing index (NWI). Ecological economics, 2006, no. 58 (1), pp. 119-133.

8. Fukuyama F. Trust: The social virtues and the creation of prosperity. New York, Free press, 1995, 480 p.

9. Bravo G. The Human sustainable development index: New calculations and a first critical analysis. Ecological indicator, 2014, no. 34 (A), pp. 145-150.

10. Fukuyama F. The end of history and the last man. New York, Free press, 2006, 446 p.

11. Böhringerab C., Patrick E.P. Jochem. Measuring the immeasurable - a survey of sustainability indices. Ecological economics, 2007, no. 63 (1), pp. 1-8.

12. Fukuyama F. The great disruption: Human nature and the reconstitution of social order. New York, Free press, 1999, $354 \mathrm{p}$.

13. O'Neil P. Essentials of comparative politics. New York, London, 2010, $781 \mathrm{p}$.

14. Charmes J., Wieringa S. Measuring women's empowerment: An assessment of the gender-related development index and the gender empowerment measure. Journal of Human Development, 2003, no. 4, iss. 3, pp. 419-435.

15. Leigh A., Wolfers J. Happiness and the human development index: Australia is not a paradox. Australian Economic Review, 2006, no. 39 (2), pp. 176-184.

16. Smith L.M, Case J.L., Smith H.M., Harwell L.C., Summers J.K. Relating ecosystem services to domains of human well-being: Foundation for a US index. Ecological Indicators, 2013, no. 28, pp. 79-90.

17. Otchet po itogam deiatel'nosti Rospatenta [Report on Rospatent activity results]. Available at: https://rospatent.gov.ru/content/uploadfiles/otchet_rp_2018.pdf (accessed 17.04.2021). 
18. McGillivray M., Clarke M. Understanding human well-being. New York, United Nations University Press, 2006, 386 p.

19. Wills E. Spirituality and subjective well-being: Evidences for a new domain in the personal well-being index. Journal of Happiness Studies, 2009, no. 10 (1), pp. 49-69.

20. Delhey J., Kroll C. A "happiness test" for the new measures of national well-being: How much better than GDP are they? Human happiness and the pursuit of maximization. Springer, Dordrecht, 2013, pp. 191-210.

Оригинальность $82 \%$

Получено 22.04.2021 Принято 17.05.2021 Опубликовано 30.09.2021

\section{G.A. Volkovitskaya}

\section{TOPICAL ASPECTS OF METHODOLOGIES FOR MEASURING QUALITY OF LIFE}

The Human Development Index (HDI) provided a milestone for tracking progress in human development, which entailed many positive effects for the structure of ideas about human development and, in particular, a change in the development formula, where the human took the first place. This can be considered a favorable paradigmatic basis for improving well-being globally and locally in different countries. Nowadays, the significance of the HDI takes on new significance, where new dimensions must be taken into account.

The humanistic approach, as the structural basis of the HDI, shows that the modern world scales the range of choice for everyone who seeks self-improvement, learning, and creative work. According to the author, the development of indices is impossible without looking at the creative potential of nations, as well as individualistic features that have already reached the global scale.

The paper examines the concept of sustainability (environmental friendliness) of labor, as a key element of the international index of happiness and well-being. The paper contains an analysis of the variation of the trust index, which is based on creative development, taking into account the innovative possibilities associated with patenting. As an evidence option in the chain of environmental friendliness of work-creative development, statistics on patenting and registration of startups are presented. Our study indicates that confidence can become a new indicator to assess the effectiveness of management measures. The former may be used as both for calculations and addressing the existing global challenges. The relevance of the confidence index is ranked by an ability to respond quickly in assessing public policy measures. It is also suitable for assessing the vulnerability of economic indicators and factors during crises.

Keywords: human development index, patenting, trust, labor sustainability, environmental friendliness of labor.

Galina A. Volkovitskaya - Candidate of Sociological Sciences, Associate Professor, Department of Education Management and Human Resource Management, Institute of Economics and Management, Herzen State Pedagogical University of Russia, Saint Petersburg, Russia, e-mail: galialap@mail.ru.

Received 22.04.2021 Accepted 17.05.2021 Published 30.09.2021 